\title{
max \\ Dynamic Model of Impact Energy Absorption by a Conveyor Belt in Interaction with the Support System
}

\author{
Daniela Marasova ${ }^{1, *}$, Miriam Andrejiova ${ }^{2}\left(\mathbb{D}\right.$ and Anna Grincova ${ }^{3}$ (D) \\ 1 Faculty of Mining, Ecology, Process Control and Geotechnology, Technical University of Kosice, \\ Park Komenskeho 14, 04200 Kosice, Slovakia \\ 2 Faculty of Mechanical Engineering, Technical University of Kosice, Letna 9, 04200 Kosice, Slovakia; \\ miriam.andrejiova@tuke.sk \\ 3 Faculty of Electrical Engineering and Informatics, Technical University of Kosice, Letna 9, \\ 04200 Kosice, Slovakia; anna.grincova@tuke.sk \\ * Correspondence: daniela.marasova@tuke.sk; Tel.: +421-55-602-3123
}

check for updates

Citation: Marasova, D.;

Andrejiova, M.; Grincova, A

Dynamic Model of Impact Energy

Absorption by a Conveyor Belt in

Interaction with the Support System.

Energies 2022, 15, 64. https://

doi.org/10.3390/en15010064

Academic Editor: Davide Astolfi

Received: 6 December 2021

Accepted: 21 December 2021

Published: 22 December 2021

Publisher's Note: MDPI stays neutral with regard to jurisdictional claims in published maps and institutional affiliations.

Copyright: (C) 2021 by the authors. Licensee MDPI, Basel, Switzerland. This article is an open access article distributed under the terms and conditions of the Creative Commons Attribution (CC BY) license (https:// creativecommons.org/licenses/by/ $4.0 /)$.

\begin{abstract}
Measurements of the dynamic load of conveyor belts of identical strengths were used to evaluate and compare the data for belts with and without a support system. The goal was to identify the effects of the support system in terms of a relative amount of impact energy absorbed by a conveyor belt. A dynamic model was designed based on selected parameters of the impact process. Damage to conveyor belts, caused by the absorption of impact energy, was evaluated using the applied methods of mathematical statistics.
\end{abstract}

Keywords: rubber-textile conveyor belt; support system; puncture resistance; absorbed energy

\section{Introduction}

Due to the fact that conveyor belts are permanently exposed to dynamic load during their utilisation, it is necessary to understand their dynamic characteristics. Dynamic characteristics of conveyor belts affect smooth conveyance, especially in continuous conveyance. Failures caused by conveyor belt malfunctions that result from poor dynamic characteristics consequently incur high financial losses due to conveyor belt ruptures at belt joints or due to damage to conveyor belts $[1,2]$. Conveyor belts are the most expensive structural elements of belt conveyors and the costs of conveyor belts represent around $40-60 \%$ of the total operating costs of belt conveyance of materials [3].

The kinematic and dynamic processes that run at transfer chutes are very complex. As much as $60 \%$ of damage to conveyor belts occurs particularly at chutes. Reliability of chutes in belt conveyance represents a serious problem; therefore, there are efforts aimed at finding methods of how to reduce the number of chutes as the sources of potential failures [4]. Hence, conveyance systems with a large number of chutes exhibit higher complexity and are associated with higher energy consumption and maintenance cost. Provided the chutes are used in line with respective operating requirements, their optimal design significantly affects the service life of conveyor belts and associated energy consumption [5]. Chutes are the points where the energy loss occurs due to the dynamic impact and a consequent absorption of impact energy by a conveyor belt [6] and due to rotating pieces of a conveyed material.

Dynamic characteristics of belts existing in a dynamic impact process are difficult to examine during the belt operation; conveyor belts should therefore be examined in laboratory conditions (by simulations) $[7,8]$. The absorption ability of composite materials is an important parameter that affects dynamic behaviour of the structures [9]. A standard laboratory method for measuring dynamic properties is, for example, measuring the vibration-damping properties of composite materials, including conveyor belts [10]. Various testing devices have been constructed to facilitate laboratory testing of the dynamic impact process; for example, the test equipment at the Technical University of Wroclaw [11] 
or the test equipment at the Technical University of Košice, which uses a laser distance sensor to measure a trajectory of the falling load [12]. Laboratory research into punctures in steel-cord conveyor belts was carried out by many others, including authors of papers [13] and [14], who have developed a magnetic high-resolution diagnostic device for steel cord conveyor belts. In addition to monitoring belts during their use in belt conveyors, this device can also be used in laboratories for testing puncture resistance of belts.

A support system is an important structural element of the chutes as it eliminates damage to conveyor belts in terms of punctures. At the chutes, material particles change their direction and velocity; this causes wearing of conveyor belts and punctures made by larger pieces of materials [15]. Experimental investigations conducted by many authors indicated that a support system design has a strong effect on energy consumption during the operation of belt conveyors and on damage to conveyor belts [16-20]. Ambriško et al. [17] applied the DOE method and carried out experimental measurements to create regression models describing a correlation between the tension load and the height at a given weight for two types of conveyance systems-with and without the support system. The effects of carrying idlers on energy consumption of a belt conveyor were discussed in the paper [18]. Loading of carrying idlers used in belt conveyors was investigated by the authors of paper [19], and an analysis of failures of idlers based on the measurements conducted during their operation was discussed in [20]. Sensors have become crucial components in identification of conveyor belt damage [3,12,21]. The authors in [21] developed a sensor system for the detection of stones and an automatic system for bulk materials for monitoring conveyor belt damage. Kovanic et al. proposed a method of measuring an impactor trajectory during the dynamic impact load using a laser distance sensor L-GAGE and experimental photography. This method has been experimentally tested and the results of the measurements were presented in publication [12]. Blažej et al. developed a magnetic sensor for monitoring steel-cord conveyor belts [3].

Dynamic characteristics have been investigated by many authors. For example, papers $[22,23]$ investigated into long belt conveyance systems in terms of reducing production costs and optimise conveyor performance. Lodewijks [24] conducted the modelling of stresses in a conveyor belt during its launch and stoppage. Dynamic behaviour of a conveyance system was mathematically described by applying an analytical approach and the Finite Element Method (FEM). Authors Junxia Li and Xiaoxu Pang simulated various factors that affect longitudinal vibrations of belt conveyors and they proposed strategies for eliminating them [25]. The simulation approach proposed by those authors facilitates better accuracy of designing the dynamics of belt conveyors. The authors of papers [26,27] dealt with the stability of the motions of conveyor belts and bulk materials on long conveyor belts and proposed novel designs of actuators with the aim of reducing stresses in conveyor belts. Many of these topics address conveyance systems in terms of their dynamics, but they are not directly associated with modelling the dynamics that occur during the impact process. Modelling the dynamics of conveyance systems equipped with a support system is currently being investigated by only a few authors in their articles [28,29].

The present article, in particular, addresses the absence of research into a dynamic impact process and proposes several dynamic models while applying selected statistical methods. Within the creation of dynamic models, the research objectives were to identify and compare the amounts of absorbed energy before the occurrence of damage to the conveyor belt (puncture) which leads to belt decommissioning. The authors wanted to verify the following hypothesis: "Do the drop hammer weight, impact height, and support system absence/presence have a significant effect on a relative amount of absorbed energy before a puncture occurs?" The main goal of the research was to create a model of a correlation between the relative amount of absorbed energy and the selected parameters.

The objectives of this experimental investigation were as follows:

Identification and comparison of the amounts of absorbed energy before the occurrence of damage to conveyor belts (puncture) which leads to belt decommissioning. 
Identification of the effects of parameters (drop hammer weight, impact height, support system absence/presence) on a relative amount of absorbed energy before a puncture occurs.

Creation of a model of a correlation between the relative amount of absorbed energy and the selected parameters.

\section{Materials and Methods}

\section{Test Equipment}

The test equipment which was used in the experiments is shown in Figure 1. A more detailed description of the equipment is presented in papers [30]. The test equipment facilitates recording the drop hammer height and magnitudes of the tension force and the impact force over time. For the purpose of our experiment, we recorded the drop hammer height (at the impact and when bouncing) every millisecond. The measurements were carried out for two different assemblies-with and without the support system. The upper limits for the drop hammer weight and impact height were determined in order to avoid destruction of the test specimen. These limits were applied in the analyses of the measurements carried out with and without engaging the support system.

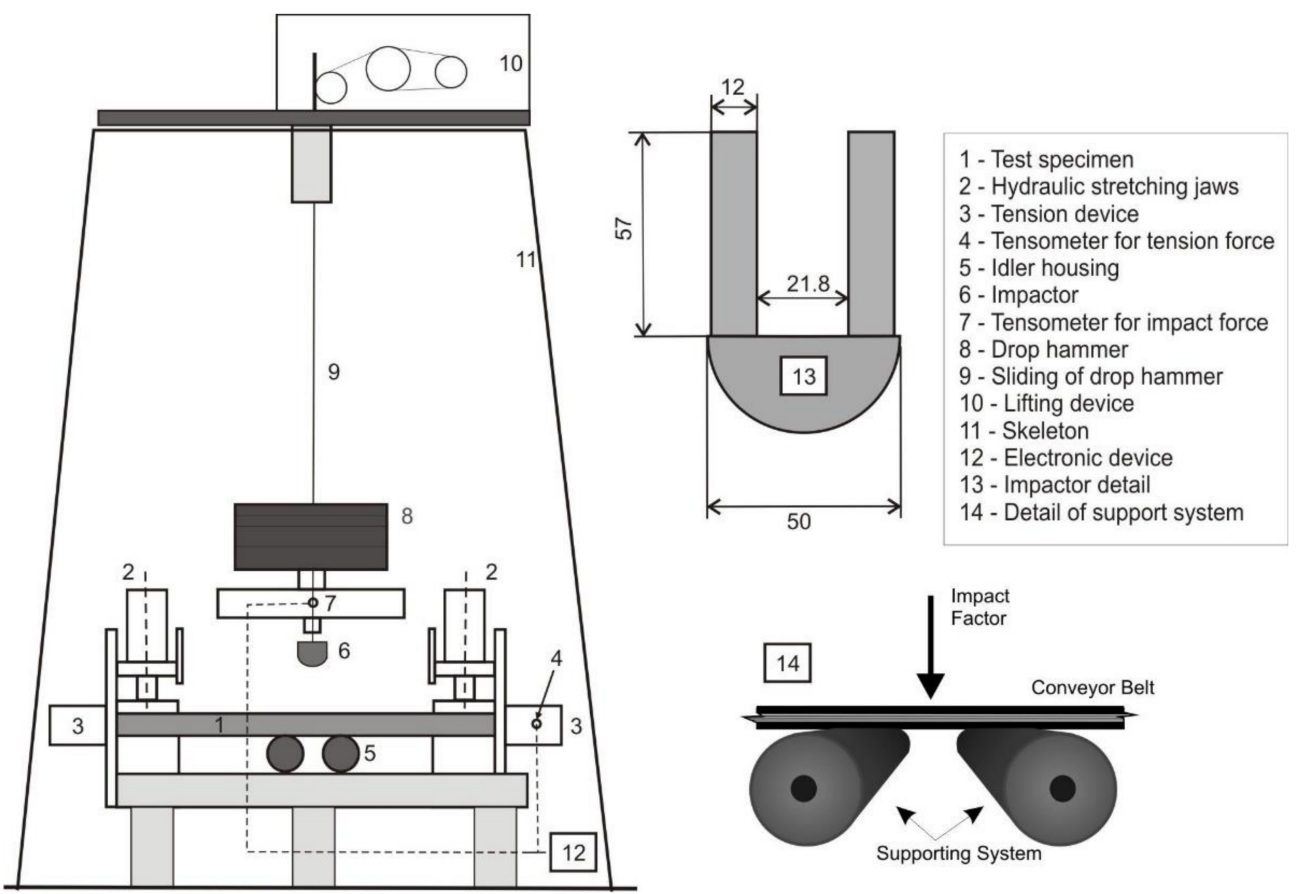

Figure 1. Test equipment scheme.

The support system consisted of two steel rollers with a diameter of $80 \mathrm{~mm}$ and an axial distance of $160 \mathrm{~mm}$. The point of impact of the drop hammer was located between the rollers. The spherical impactor (Figure 1) simulated an impact of a bulk, brittle material. In the experiments, the simulated weights of the falling material were 50, 60, 70, 80, 90, and $100 \mathrm{~kg}$. Drop heights ranged from 1 to $2.6 \mathrm{~m}$, with $0.2 \mathrm{~m}$ increments. The investigated belt was a rubber-textile conveyor belt, type P2500 (P means the polyamide textile layer and 2500 expresses the rigidity of the conveyor belt $\left.\left[\mathrm{Nmm}^{-1}\right]\right)$. Each specimen was sized $1400 \times 160 \mathrm{~mm}$. The specimens were prepared following the methodology described in paper [31]. The tension force applied in the experiments was $40 \mathrm{kN}$, representing 1/10 of the belt strength per millimetre of its width (manufacturer's recommendation). 


\section{Theory/Calculation}

\subsection{Absorbed Energy}

With known heights to which the material bounced-back, while considering the differences in potential energies of an object prior to the impact and after the impact, it was possible to identify the amount of energy absorbed by the conveyor belt while neglecting the effects of the environment. The underlying principle is shown in Figure 2.

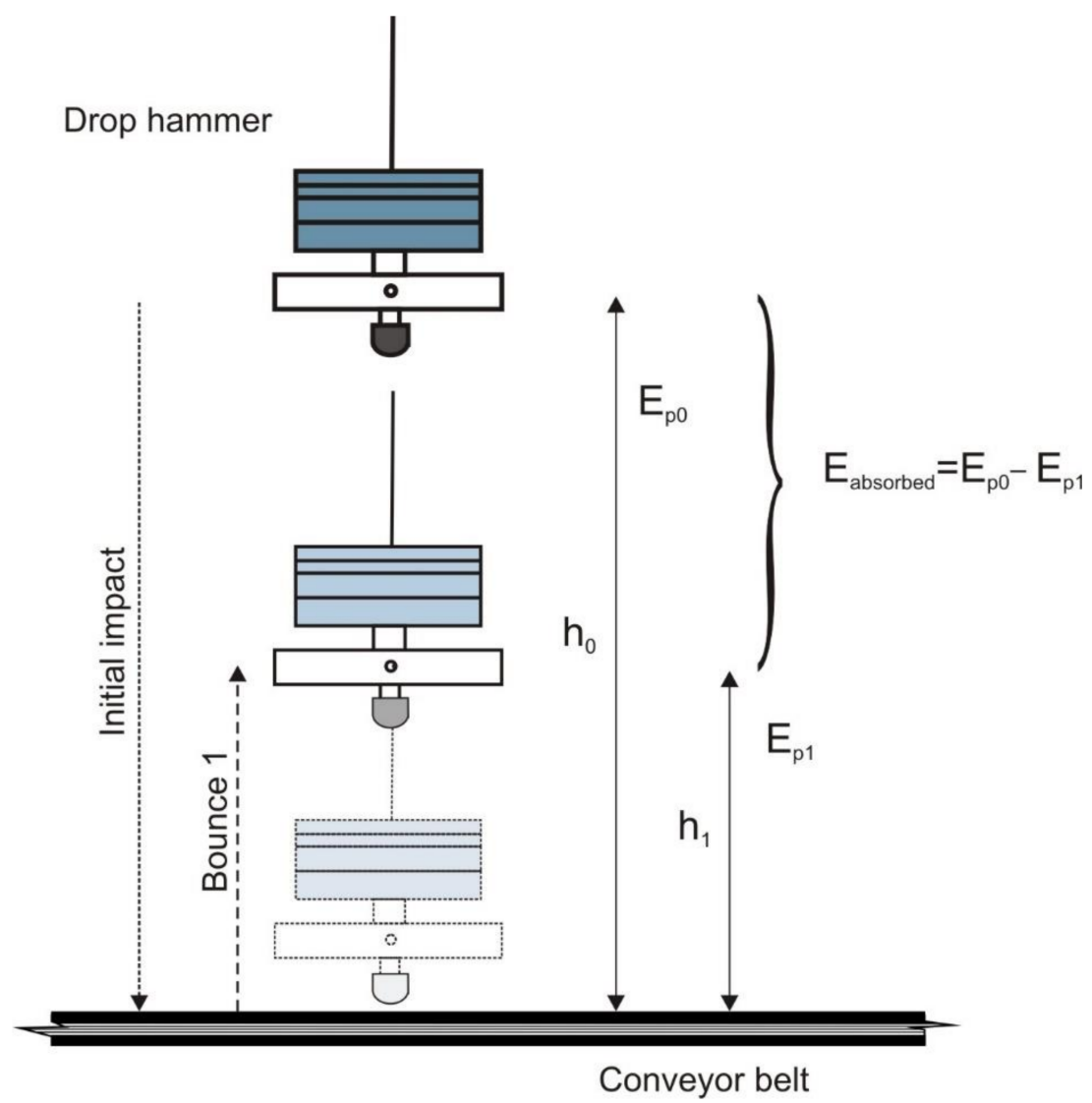

Figure 2. Impact and Bounce 1 of the drop hammer.

The absolute value of the amount of energy $E_{\text {absorbed }}$ absorbed after Bounce 1 was calculated using the following equation:

$$
E_{a b s o r b e d}=E_{p 0}-E_{p 1}
$$

wherein $E_{p 0}$ is the amount of potential energy prior to the first impact, and $E_{p 1}$ is the amount of potential energy after the first bounce (Bounce 1).

The amount of impact energy (in \%) absorbed by the conveyor belt after the first impact was calculated using a relative amount of absorbed energy $E_{\text {relat }}$. The following equation was used:

$$
E_{\text {relat }}=\frac{E_{p 0}-E_{p 1}}{E_{p 0}} \times 100 \%=\left(1-\frac{E_{p 1}}{E_{p 0}}\right) \times 100 \% .
$$

The following equation applies to the $\mathrm{i}^{\text {th }}$ bounce $(i=1,2, \ldots)$ of the drop hammer on the conveyor belt:

$$
E_{\text {relat }, i}=\frac{E_{p i-1}-E_{p i}}{E_{p i-1}} \times 100 \%=\left(1-\frac{E_{p i}}{E_{p i-1}}\right) \times 100 \% .
$$




\subsection{Evaluation Methods}

The values were compared using the methods of statistical induction-hypothesis testing. Normality of data sets was verified using the Shapiro-Wilk test of normality. A comparison of two dependent data sets was carried out using the paired $t$-test. The null hypothesis acceptance or rejection was based on a $p$-value. In principle, if the $p$-value is lower than the significance level $\alpha$, then the null hypothesis is rejected in favour of the alternative hypothesis. If the $p$-value equals to or is higher than the predetermined significance level $\alpha$, then the null hypothesis is not rejected.

The correlations between the output variable and selected input variables were investigated using regression and correlation analyses. The following standard linear regression model was considered:

$$
Y=\beta_{0}+\sum_{j=1}^{k} \beta_{j} X_{j}+\varepsilon
$$

wherein $\beta_{0}$ and $\beta_{j}$ for $\mathrm{j}=1,2, \cdots, \mathrm{k}$ are the model parameters; $\mathrm{Y}$ is the input (dependent) variable; variables $X_{j}, \mathrm{j}=1,2, \cdots, \mathrm{k}$ represent $\mathrm{k}$ independent input variables; and $\varepsilon$ is the random error. Model parameters were identified using the method of least squares.

Statistical significance of the regression model, or its parameters, was verified using the tests of statistical significance. The strengths of the effect of $Y$ variable and the effects of $\mathrm{k}$ variables were expressed by means of the coefficient of multiple determination $\mathrm{r}^{\wedge} 2$. The coefficient values ranged within the $<0 ; 1>$ interval. In principle, as its value approaches 1 , the correlation becomes stronger.

\section{Results}

Experimental tests were carried out with a P2500 rubber-textile conveyor belt. The measurements were carried out with two different assemblies-with and without the support system. During the experiments without the support system, no significant damage to the conveyor belt specimen was observed. With the support system engaged, destruction (punctures) of the conveyor belt specimen was observed at certain drop hammer weights and impact heights. A puncture is the type of damage that occurs to the top cover layer, the carcass and the bottom cover layer of the belt.

The input parameters were the weight $m$ of the falling material and the impact height $h$.

Figure 3 shows the occurrence of punctures during the experiments. In order to facilitate a comparison of the amounts of absorbed energy with and without using the support system, a sub-set of the measurements, out of the whole set of the obtained results, was analysed for the weights ranging from 50 to $80 \mathrm{~kg}$ and for the impact heights ranging from 1 to $2 \mathrm{~m}$ at 4 consecutive bounces of the drop hammer.

The time course of the measured heights at the impact of the drop hammer onto the conveyor belt (at a certain weight $m$ and a certain impact height $h$ ) is shown in Figures 4 and 5 . The graphs illustrate the impacts of the drop hammer onto the conveyor belt with and without the support system.

The individual drop hammer bounces exhibited apparent differences in the experiments with (SS) and without using the support system (WSS). 


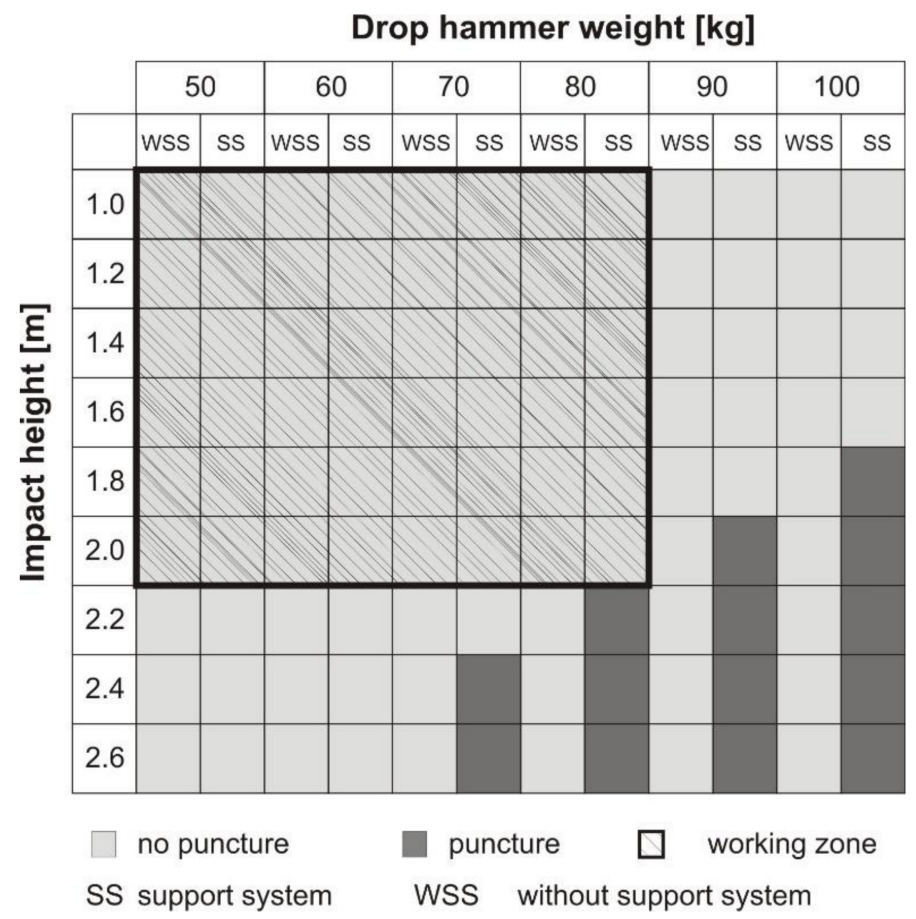

Figure 3. Puncture occurrence.
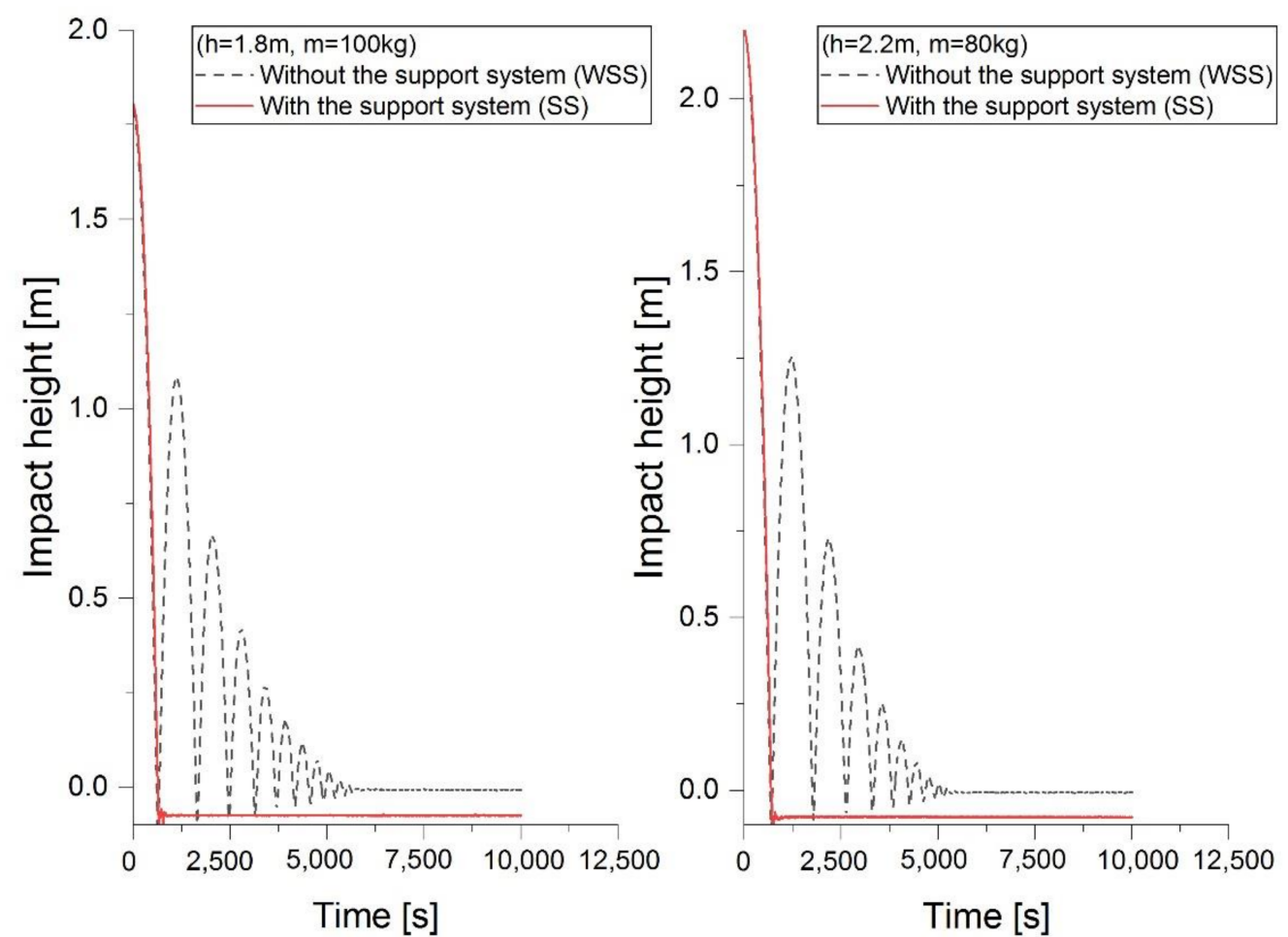

Figure 4. Time course of the drop hammer impacts with a final puncture. 

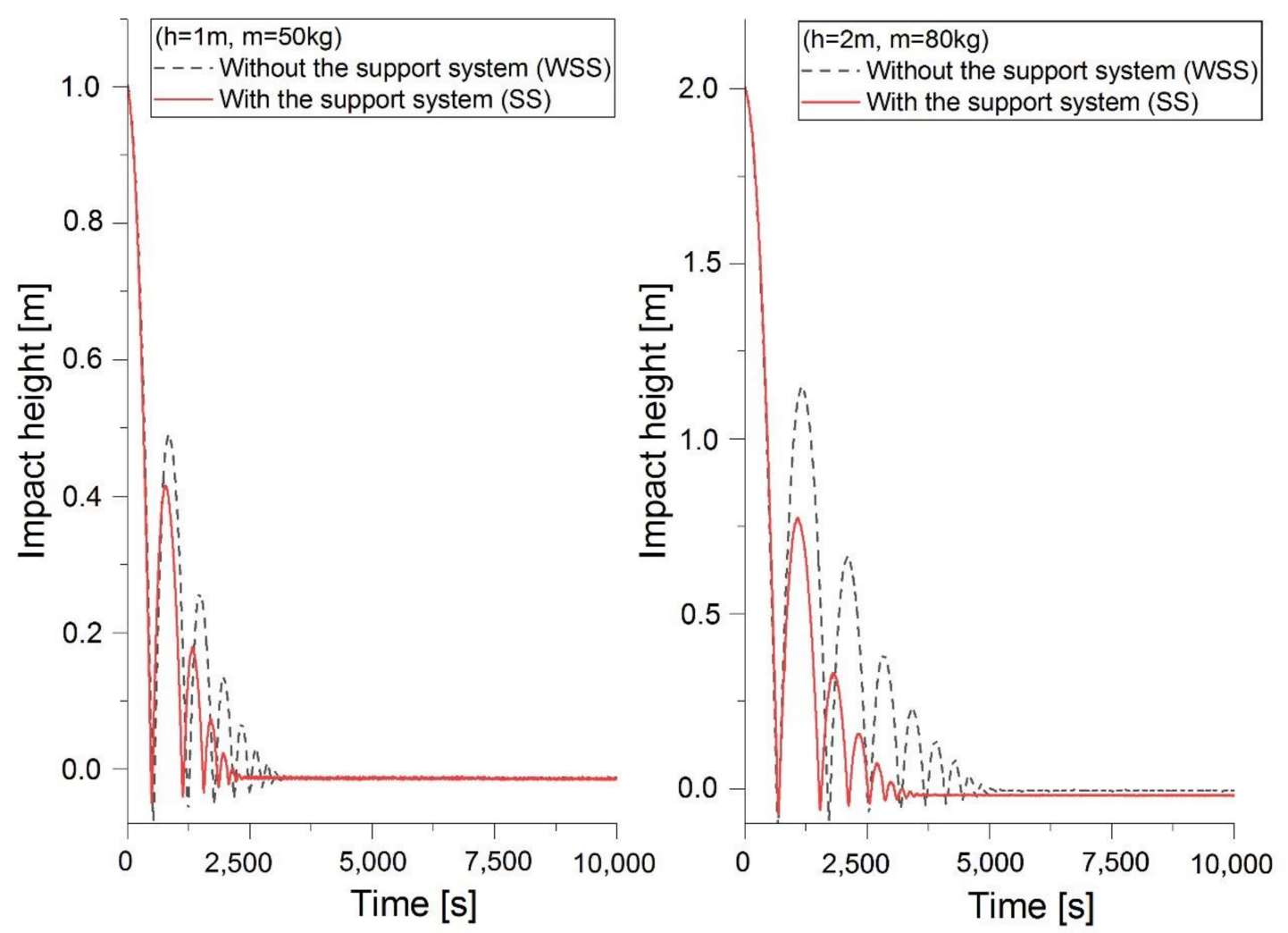

Figure 5. Time course of the drop hammer impacts.

\subsection{Identification and Comparison of a Relative Amount of Absorbed Energy}

Relative amounts of absorbed energy at first four bounces were expressed using Equation (3).

At drop hammer weights ranging from $50 \mathrm{~kg}$ to $80 \mathrm{~kg}$, with $10 \mathrm{~kg}$ increments, impacts from six different heights were simulated. Figure 6 shows relative amounts of absorbed energy at first four bounces of the drop hammer on the conveyor belt. Two impact heights of the drop hammer, $100 \mathrm{~cm}$ and $200 \mathrm{~cm}$, were applied to all of the tested drop hammer weights and to both system assemblies-with and without the support system.

For each drop hammer weight and each impact height, an average value of the relative amount of absorbed energy was determined. There were minimum differences between the obtained values for both impact heights, all impact weights and both system assemblies (with the support system (SS) and without the support system (WSS)) (Figure 6).

The initial comparison of the obtained values indicated a slight decrease in the values of the relative amount of absorbed energy with a growing number of bounces in both system assemblies (with and without the support system).

Average values of the relative amount of absorbed energy at the given weights, depending on whether the support system was or was not engaged, are listed in Table 1. 


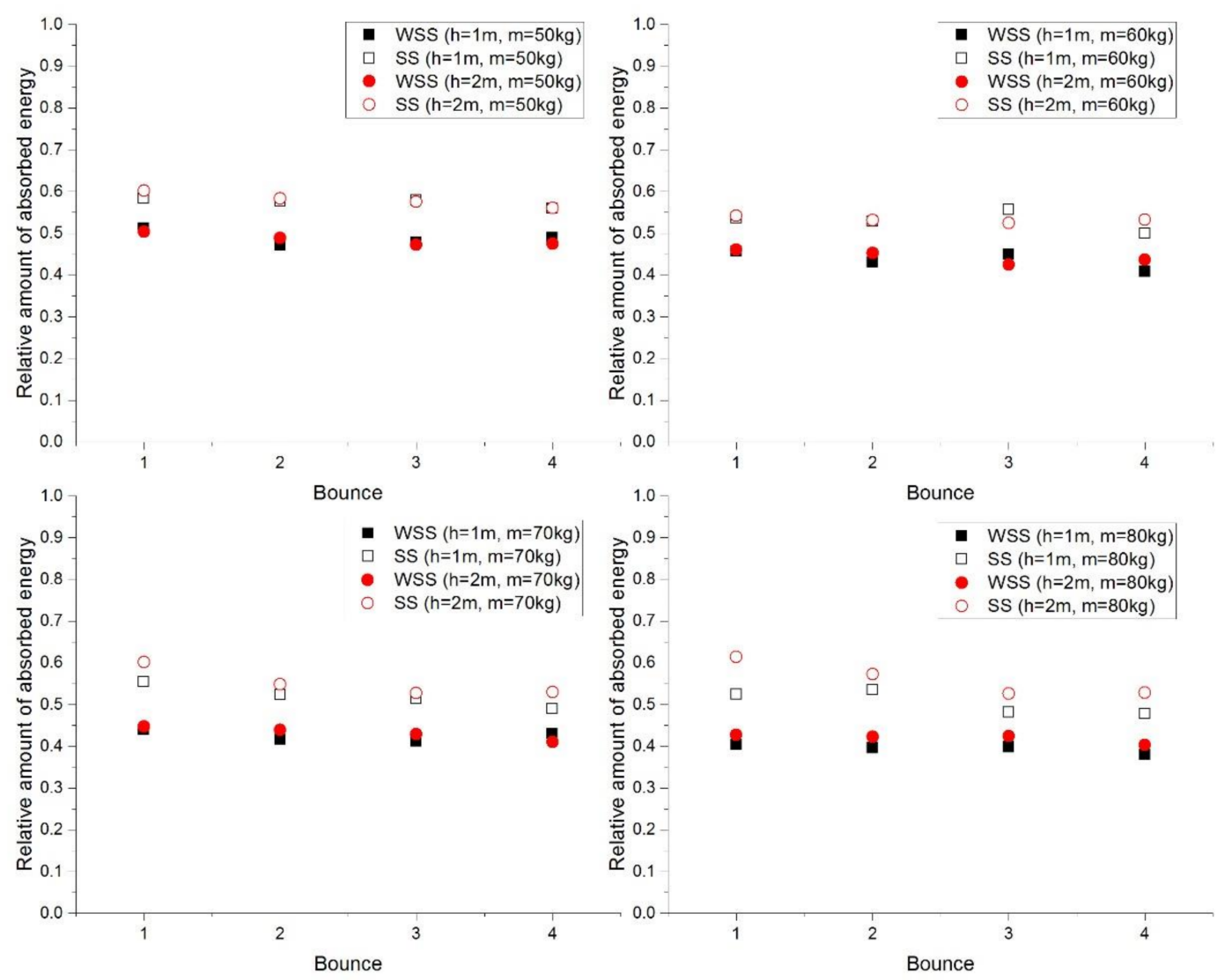

Figure 6. Relative amounts of absorbed energy.

Table 1. Average values of the relative amount of absorbed energy.

\begin{tabular}{|c|c|c|c|c|c|c|c|c|}
\hline \multirow{3}{*}{$\begin{array}{c}\begin{array}{c}\text { Parameters } \\
\text { Weight }\end{array} \\
\text { Support System }\end{array}$} & \multicolumn{8}{|c|}{ Drop Hammer Weight/Support System } \\
\hline & \multicolumn{2}{|c|}{$50 \mathrm{~kg}$} & \multicolumn{2}{|c|}{$60 \mathrm{~kg}$} & \multicolumn{2}{|c|}{$70 \mathrm{~kg}$} & \multicolumn{2}{|c|}{$80 \mathrm{~kg}$} \\
\hline & WSS & SS & WSS & SS & WSS & SS & WS & SS \\
\hline Bounce & & & & & & & & \\
\hline Bounce 1 & 0.51 & 0.58 & 0.46 & 0.54 & 0.45 & 0.57 & 0.41 & 0.56 \\
\hline Bounce 2 & 0.48 & 0.57 & 0.44 & 0.53 & 0.43 & 0.54 & 0.41 & 0.54 \\
\hline Bounce 3 & 0.48 & 0.56 & 0.44 & 0.53 & 0.42 & 0.52 & 0.40 & 0.50 \\
\hline Bounce 4 & 0.48 & 0.62 & 0.44 & 0.55 & 0.42 & 0.54 & 0.41 & 0.54 \\
\hline
\end{tabular}

The experimental measurements indicated that the effect of the impact height on the relative amount of impact energy absorbed at a given drop hammer weight was insignificant. This applied equally to both system assemblies-with (SS) and without the support system (WSS).

Nevertheless, there were some indications that a drop hammer weight affects a relative amount of absorbed impact energy. Apparently, the range of the values of the relative amount of absorbed energy is wider.

The effect of the presence of the support system on the relative amount of absorbed impact energy was evident (Figure 7, Table 1). With the support system engaged, the conveyor belt was able to absorb, for example at Bounce 1, 54\% to $58 \%$ of impact energy, depending on the impact height and drop hammer weight. Without the support system, the conveyor belt was able to absorb $41 \%$ to $51 \%$ of energy at Bounce 1, depending on the impact height and drop hammer weight. 


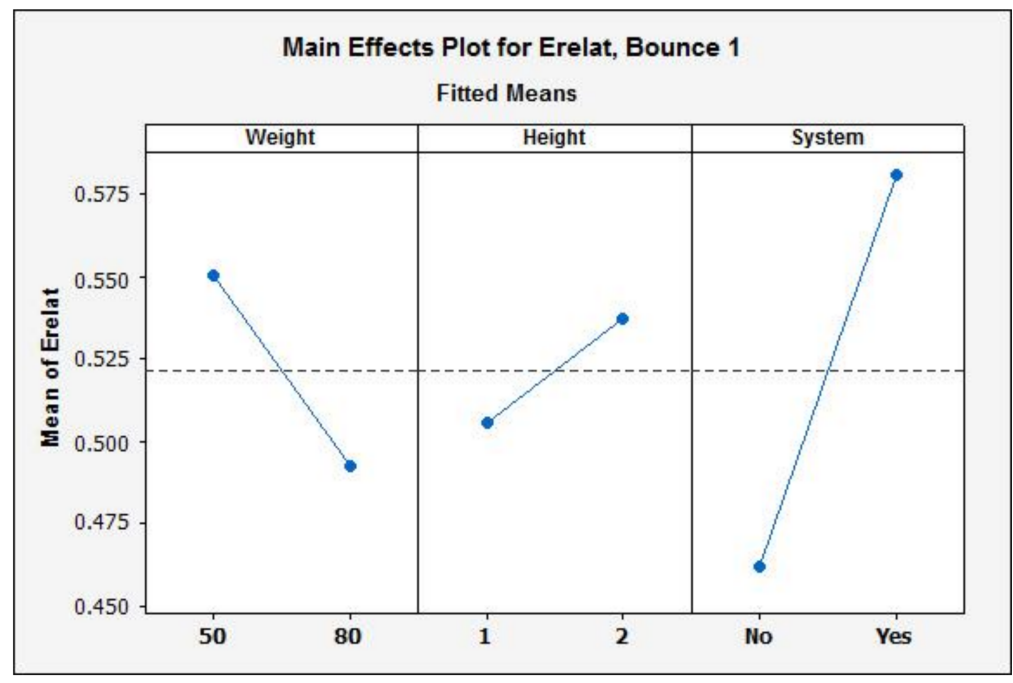

Figure 7. Graphical representation of the effects (Bounce 1).

The values obtained by measurements were compared using the testing methods. The measured values of relative absorption at the individual weights and impact heights met the normality requirement, which was verified by the Shapiro-Wilk test of normality $(p$-value $<\alpha)$. A paired comparison of the values identified for the two system assemblies (with and without the support system) at each drop hammer weight and impact height was verified using a paired $t$-test. The resulting $p$-values obtained by the paired testing are listed in Table 2.

Table 2. Test results-paired $t$-test $(\alpha=0.05)$.

\begin{tabular}{|c|c|c|c|c|}
\hline \multirow{2}{*}{$\begin{array}{c}\text { Impact Height } \\
{[\mathrm{m}]}\end{array}$} & \multicolumn{4}{|c|}{ Drop Hammer Weight ( $p$-Value) } \\
\hline & $50 \mathrm{~kg}$ & $60 \mathrm{~kg}$ & $70 \mathrm{~kg}$ & $80 \mathrm{~kg}$ \\
\hline 1.0 & 0.0429 & 0.0058 & 0.0006 & 0.0010 \\
\hline 1.2 & 0.0051 & 0.0065 & 0.0004 & 0.0010 \\
\hline 1.4 & 0.0221 & 0.0018 & 0.0006 & 0.0015 \\
\hline 1.6 & 0.0313 & 0.0081 & 0.0014 & 0.0106 \\
\hline 1.8 & 0.0115 & 0.0107 & 0.0005 & 0.0082 \\
\hline 2.0 & 0.0061 & 0.0006 & 0.0004 & 0.0109 \\
\hline
\end{tabular}

The results of the testing indicated that there were statistically significant differences in relative amounts of potential energy, and they depended on the conditions in which the experiments were carried out (i.e., with or without the support system, at a constant weight and impact height).

\subsection{Monitoring the Effects of Selected Parameters on the Value of the Relative Amount of Absorbed Energy}

The purpose of this investigation was to identify the variables (factors), or interactions between them, which have significant effects on the output variable (a value of the relative amount of absorbed energy) at the $i^{\text {th }}$ bounce of the drop hammer on the conveyor belt. The tests were carried out for two different system assemblies (System variable): without the support system (No) and with the support system (Yes). The minimum impact height of the drop hammer in the working zone (Height variable) was determined as $1 \mathrm{~m}$, and the maximum height was $2 \mathrm{~m}$. The minimum weight of the drop hammer was $50 \mathrm{~kg}$ while the maximum weight was $80 \mathrm{~kg}$ (Weight variable). The input parameters and their levels are presented in Table 3. 
Table 3. Input parameters for the DOE method.

\begin{tabular}{cccc}
\hline \multirow{2}{*}{ Level } & Weight $[\mathrm{kg}]$ & Height $[\mathrm{m}]$ & \multicolumn{2}{c}{ System } \\
& A & B & No \\
\hline Lower $(-)$ & 50 & 1.0 & Yes \\
\hline Upper (+) & 80 & 2.0 & \\
\hline
\end{tabular}

The effects of the main input variables $(\mathrm{A}, \mathrm{B}, \mathrm{C})$ for all of the monitored bounces are listed in Table 4. Significance of the effects of individual variables was tested by a $t$-test and by identifying a $p$-value.

Table 4. Effects of main variables.

\begin{tabular}{cccccc}
\hline Bounce & & Weight (A) & Height (B) & System (C) & R-Squared \\
\hline 1. & effect & -0.064 & 0.031 & 0.119 & $91.35 \%$ \\
& $p$-value & 0.040 & $0.221^{*}$ & 0.005 & \\
\hline 2. & effect & -0.048 & 0.022 & 0.125 & $94.15 \%$ \\
& $p$-value & 0.018 & $0.148^{*}$ & 0.001 & \\
\hline 3. & effect & -0.069 & 0.015 & 0.098 & $94.58 \%$ \\
& $p$-value & 0.003 & $0.243^{*}$ & 0.001 & \\
\hline 4. & effect & -0.082 & -0.035 & 0.156 & $95.73 \%$ \\
& $p$-value & 0.005 & $0.070^{*}$ & 0.0001 & \\
\hline
\end{tabular}

: $p$-value $>\alpha, \alpha=0.05$.

A graphical representation of the main effects of all factors at Bounce 1 is shown in Figure 7. A positive effect value means that, as the variable shifts from the lower level to the upper level, its effect increases and so does the output value. A negative value of the effect of the drop hammer weight means that, as the weight increases, with the other conditions being constant, the output variable slightly decreases.

Results of the DOE method confirmed the conclusions made on the basis of the experimental measurements. An analysis of the results indicated that System variable (C) and Weight variable (A) had significant effects on the output variable. On the other hand, the effect of the Impact Height (C) was negligible in terms of the amount of absorbed impact energy at the given drop hammer weight, regardless of the bounce sequence number $(p$-value $>\alpha)$.

In this case, only the Weight (A) and System (C) main variables exhibited statistically significant effects. Therefore, the model of a complete three-factor experiment was adjusted as follows:

$$
E_{\text {relat }, i}=b_{0}+b_{1} \text { Weight }+b_{2} \text { System, }
$$

wherein $E_{\text {relat }, i}$ is the value of the relative amount of absorbed energy at $i^{\text {th }}$ bounce and $b_{0}$, $b_{1}, b_{2}$ are the point estimates of the model parameters. Models (5), (6), (7), and (8) were created based on Equation (4).

The values of the parameters equalled half of the respective effect. The total informative value of the model was identified based on the coefficient of multiple determination $\mathrm{R}$-squared (Table 4). High values of the R-squared coefficient at all the bounces mean that the created models explain the variability of the variables very well.

\subsection{Creation of a Model of Correlations between the Relative Amount of Absorbed Energy and Selected Parameters}

The purpose of this investigation was to find a regression model that would express the correlations between the relative amount of absorbed potential energy $E_{\text {relat }}$ and four independent variables (Height, Weight, Bounce and System); the created model is as follows:

$$
E_{\text {relat }}=\beta_{0}+\beta_{1} \text { Height }+\beta_{2} \text { Weight }+\beta_{3} \text { Bounce }+\beta_{4} \text { System }+\varepsilon,
$$


wherein $\beta_{0}$ and $\beta_{j}$ for $j=1,2,3,4$ are the model parameters and $\varepsilon$ is the random error.

Height was the input variable ranging from $1 \mathrm{~m}$ to $2 \mathrm{~m}$, with $0.2 \mathrm{~m}$ increments and Weight ranged from 50 to $80 \mathrm{~kg}$, with $10 \mathrm{~kg}$ increments. Bounce variable acquired four different values (1 for Bounce 1; 2 for Bounce 2; 3 for Bounce 3; and 4 for Bounce 4). System was a dichotomic variable, and it was converted into a numerical variable with two values: 1 for the support system being present (SS) and 0 for the support system being absent (WSS). The output variable $E_{\text {relat }}$ was a continuous variable that ranged from 0 to 1 .

The point estimate of the model (Model I) was as follows:

$$
E_{\text {relat }}=b_{0}+b_{1} \text { Height }+b_{2} \text { Weight }+b_{3} \text { Bounce }+b_{4} \text { System } .
$$

Point estimates of the parameters, as well as their statistical significance, and interval estimates of the parameters are listed in Table 5.

Table 5. Estimated values of the regression Model I parameters $(\alpha=0.05)$.

\begin{tabular}{ccccccc}
\hline Parameter & Estimate & $\begin{array}{c}\text { Standard } \\
\text { Error }\end{array}$ & t-Stat & $\boldsymbol{p}$-Value & \multicolumn{2}{c}{$\begin{array}{c}\text { 95\%-Confidence Interval } \\
\text { Lower }\end{array}$} \\
\hline Intercept & 0.565 & 0.0117 & 48.311 & $<0.0001$ & 0.5428 & 0.5890 \\
Height & 0.008 & 0.0045 & 1.674 & 0.096 & -0.0013 & 0.0163 \\
Weight & -0.002 & 0.0001 & -13.800 & $<0.0001$ & -0.0021 & -0.0016 \\
Bounce & -0.005 & 0.0014 & -3.845 & $<0.0001$ & -0.0080 & -0.0026 \\
System & 0.101 & 0.0030 & 33.641 & $<0.0001$ & 0.0955 & 0.1074 \\
\hline
\end{tabular}

Results of the testing indicated that Model I was a statistically significant regression model $\left(p\right.$-value $\left.=2.8 \times 10^{-82}<\alpha\right)$ with the coefficient of determination representing 0.88 . Apparently, Height variable was not statistically significant ( $p$-value $>\alpha$ ), while the other input variables were statistically significant, i.e., they significantly affected the output variable.

A modified regression model (Model II) was as follows:

$$
E_{\text {relat }}=b_{0}+b_{1} \text { Weight }+b_{2} \text { Bounce }+b_{3} \text { System } .
$$

Point estimates of the parameters and statistical significance of the adjusted regression model are listed in Table 6.

\begin{tabular}{|c|c|c|c|c|c|c|}
\hline \multirow{2}{*}{ Parameter } & \multirow{2}{*}{ Estimate } & \multirow{2}{*}{$\begin{array}{l}\text { Standard } \\
\text { Error }\end{array}$} & \multirow{2}{*}{ t-Stat } & \multirow{2}{*}{$p$-Value } & \multicolumn{2}{|c|}{$95 \%$-Confidence Interval } \\
\hline & & & & & Lower & Upper \\
\hline Intercept & 0.577 & 0.009 & 60.317 & $<0.0001$ & 0.5584 & 0.5962 \\
\hline Weight & -0.002 & 0.0001 & -13.795 & $<0.0001$ & -0.0021 & -0.0016 \\
\hline Bounce & -0.005 & 0.0014 & -3.725 & 0.0003 & -0.0078 & -0.0024 \\
\hline System & 0.102 & 0.0030 & 33.508 & $<0.0001$ & 0.0956 & 0.1076 \\
\hline
\end{tabular}

Table 6. Estimated values of the regression Model II parameters $(\alpha=0.05)$.

The adjusted regression Model II was statistically significant $\left(p\right.$-value $\left.=5 \times 10^{-83}<\alpha\right)$ and the coefficient of determination equalled 0.88 . All of the input variables were statistically significant $(p$-value $<\alpha)$; this means that they had significant effects on the relative amount of absorbed potential energy.

A graphical representation of the empirical (real) values and the theoretical (model) values of the relative amount of absorbed energy is presented in Figure 8. 


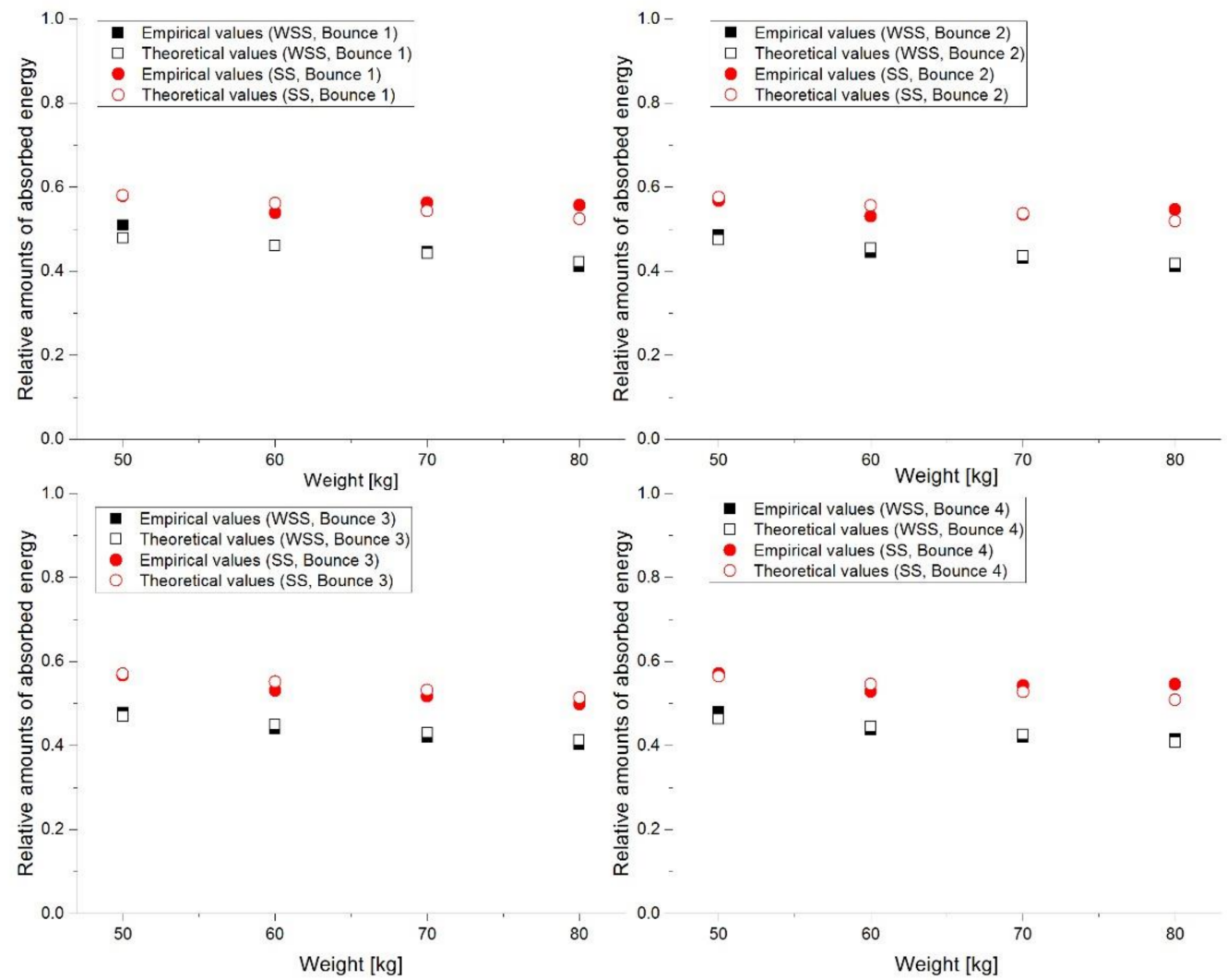

Figure 8. Empirical and theoretical values (Model II).

\section{Conclusions}

The purpose of this experimental research was to examine and compare the dynamic load of the P2500 rubber-textile conveyor belt. The resulting values of the relative amount of absorbed energy, obtained with and without engaging a support system, were compared. Experiments simulated various real conditions (impact of materials of various weights, falling from various heights). Conclusions that were made based on the experiments were as follows:

Within the identification and comparison of the amounts of absorbed energy before the occurrence of damage to the conveyor belt (puncture) which usually leads to belt decommissioning, it was observed that the tested conveyor belt absorbed, without suffering any damage, the energy of $1589 \mathrm{~kJ}$ when the support system was engaged, and $2551 \mathrm{~kJ}$ when the support system was absent, with a maximum impact weight of $100 \mathrm{~kg}$ and a maximum impact height of $2.6 \mathrm{~m}$.

Based on the results of identification of the effects of the parameters (drop hammer weight, impact height and support system absence/presence) on a relative amount of absorbed energy before a puncture occurs, it was concluded that the effect of the impact height on the relative amount of absorbed impact energy at the given drop hammer weight was not strong in any of the two system assemblies, i.e., with and without the support system. However, the effect of the drop hammer weight on the relative amount of absorbed impact energy was strong. The range of the values of the relative amount of absorbed energy was apparently wider. A relative amount of absorbed energy decreased with an increasing drop hammer weight; this applied to both system assemblies, i.e., with and without the support system. Out of all the parameters, the support system presence exhibited the most evident effect on the relative amount of absorbed impact energy. The conveyor belt equipped with a support system absorbed 50\% to $62 \%$ of the impact energy, depending on the drop hammer impact height and weight. Without the support system, 
the conveyor belt absorbed $40 \%$ to $51 \%$ of energy, depending on the drop hammer impact height and weight.

The main purpose of the research was accomplished by creating a model of correlations between the relative amount of absorbed energy and selected parameters, while the proposed dynamic model included some of the impact process parameters. The resulting regression model (8) confirmed that a drop hammer weight and presence of the support system are the parameters with a statistically significant impact on the amount of absorbed energy.

In our further research, we will carry out experimental testing of interactions between a conveyor belt and an impact bed consisting of rubber impact bars of various designs (types). We will also compare the resulting amounts of energy absorbed by the conveyor belt to those observed with a conveyor belt equipped with a conventional support system consisting of idlers. We plan to test conveyor belts of various strengths and various carcass designs.

Author Contributions: Conceptualization, M.A., D.M. and A.G.; methodology, M.A. and A.G.; software, M.A.; validation, M.A. and A.G.; formal analysis, A.G. and D.M.; investigation, M.A. and A.G.; resources, A.G.; data curation, M.A.; writing—original draft preparation, M.A., A.G. and D.M.; writing—review and editing, A.G. and D.M.; visualization, M.A.; supervision, D.M.; project administration, D.M.; funding acquisition, D.M. All authors have read and agreed to the published version of the manuscript.

Funding: This research received no external funding.

Institutional Review Board Statement: Not applicable.

Informed Consent Statement: Not applicable.

Data Availability Statement: Not applicable.

Acknowledgments: This article was prepared with the support from the project titled APVV-18-0248 "Smart belt conveyors" and the project titled VEGA 1/0168/21 "Research and application of contact and contactless methods of measuring properties of additive manufacturing products", and it was funded by National Research Agency of Slovakia, Grant No. VEGA 1/0429/18.

Conflicts of Interest: The authors declare no conflict of interest.

\section{References}

1. Saderova, J. Laboratory research of a conveyor belt with a textile carcass for mine conveying. SGEM 2018, 18, 537-544.

2. Ambrisko, L.; Marasova, D.; Grendel, P. Determination the effect of factors affecting the tensile strength of fabric conveyor belts. Eksploat. Niezawodn. 2016, 18, 110-116. [CrossRef]

3. Błażej, R.; Jurdziak, L.; Kozłowski, T.; Kirjanów, A. The use of magnetic sensors in monitoring the condition of the core in steel cord conveyor belts-Tests of the measuring probe and the design of the DiagBelt system. Meas. J. Int. Meas. Confed. 2018, 123, 48-53. [CrossRef]

4. Grujic, M.; Malindzak, D.; Marasova, D. Possibilities for reducing the negative impact of the number of conveyors in a coal transportation system. Teh. Vjesn. 2011, 18, 453-458.

5. Andrejiova, M.; Grincova, A.; Marasova, D.; Grendel, P. Multicriterial assessment of the raw material transport. Acta Montan. Slovaca 2015, 20, 26-32.

6. Grincova, A.; Andrejiova, M.; Marasova, D.; Khouri, S. Measurement and determination of the absorbed impact energy for conveyor belts of various structures under impact loading. Meas. J. Int. Meas. Confed. 2019, 131, 362-371. [CrossRef]

7. Ambrisko, L.; Marasova, D.; Cehlar, M. Investigating the tension load of rubber composites by impact dynamic testing. Bull. Mater. Sci. 2017, 40, 281-287. [CrossRef]

8. Marasova, D.; Saderova, J.; Ambrisko, L. Simulation of the Use of the Material Handling Equipment in the Operation Process. Open Eng. 2020, 10, 216-223. [CrossRef]

9. Wojtowicki, J.L.; Jaouen, L.; Panneton, R. New approach for the measurement of damping properties of materials using the Oberst beam. Rev. Sci. Instrum. 2004, 75, 2569-2574. [CrossRef]

10. Koruk, H.; Sanliturk, K.Y. On measuring dynamic properties of damping materials using beam method. In Proceedings of the 10th ASME Biennial Conference on Engineering Systems Design and Analysis, Istanbul, Turkey, 12-24 July 2010; Volume 2, pp. 127-134. 
11. Komander, H.; Hardygóra, M.; Bajda, M.; Komander, G.; Lewandowicz, P. Assessment methods of conveyor belts impact resistance to the dynamic action of a concentrated load. Eksploat. Niezawodn. 2014, 16, 579-584.

12. Kovanic, L.; Ambrisko, L.; Marasova, D.; Blistan, P.; Kasanicky, T.; Cehlar, M. Long-Exposure RGB Photography with a Fixed Stand for the Measurement of a Trajectory of a Dynamic Impact Device in Real Scale. Sensors 2021, 21, 18. [CrossRef]

13. Bajda, M.; Blazej, R.; Jurdziak, L. A new tool in belts resistance to puncture research. Min. Sci. 2016, $23,173-182$.

14. Wozniak, D.; Hardygóra, M. Method for laboratory testing rubber penetration of steel cords in conveyor belts. Min. Sci. 2020, 27, 105-117. [CrossRef]

15. Grincova, A.; Berezny, S.; Marasova, D. Regresion model creation based on experimental tests of conveyor belts against belt rips resistance. Acta Montan. Slovaca 2009, 14, 113-120.

16. Amin Almasi: Don't Fall Short with Transfer Chutes. Chem. Process 2020, 82, 23-28.

17. Ambrisko, L.; Marasova, D. Evaluation the Quality of Rubber Composites using the DOE Method. Quallity-Access Success 2017, $18,60-63$.

18. Kulinowski, P.; Kasza, P.; Zarzycki, J. Influence of design parameters of idler bearing units on the energy consumption of a belt conveyor. Sustainability 2021, 13, 437. [CrossRef]

19. Król, R.; Kisielewski, W. Research of loading carrying idlers used in belt conveyor-practical applications. Diagnostyka 2014, 15, 67-74.

20. Gładysiewicz, L.; Król, R.; Kisielewski, W. Measurements of loads on belt conveyor idlers operated in real conditions. Meas. J. Int. Meas. Confed. 2019, 134, 336-344. [CrossRef]

21. Borchart, G.; Gums, B.; Kelemens, J.; Pyrcik, J. Bulk goods separation from the stream of conveyed coal. World Min. Sufrace Undergr. 2011, 63, 15-20.

22. Zhu, L.P.; Jiang, W.L. Study on typical belt conveyor in coal mine of China. J. China Coal Soc. 2010, 35, $1916-1920$.

23. Wang, B.H.; Liu, J.P.; Lu, S. Analyzed development of the high-power and high-speed belt conveyor. Min. Mach. 2014, 42, 27-30.

24. Lodewijks, G. Dynamics of Belt Systems. Ph.D. Thesis, Delft University of Technology, Delft, The Netherlands, 14 October 1996.

25. Li, J.; Pang, X. Belt Conveyor Dynamic Characteristics and Influential Factors. Shock Vib. 2018, 2018, 1-13. [CrossRef]

26. Zuo, B.; Song, W.G.; Wan, L.L. Comparative of the belt conveyors starting "s curves" based on the traveling wave theory. Min. Mach. 2011, 39, 46-52.

27. Zhao, G.W. Experimental research on the rubber belts dynamic characteristics of the large belt conveyor. Sci. Technol. Inf. 2011, 21, 549-550.

28. Caban, L.; Marasova, D.; Ambrisko, L. Methodology of the Impact Process Applying the Finite Element Method. TEM J. Technol. Educ. Manag. Inform. 2019, 8, 775-781.

29. Ambrisko, L.; Frydrysek, K.; Erdeljan, D.J.; Marasova, D., Jr. Experimental research of a new generation of support systems for the transport of mineral raw materials. Acta Montan. Slovaca 2017, 22, 377-385.

30. Marasova, D.; Matiskova, D.; Andrejiova, M.; Grincova, A. Electromechanical Device with Sliding Ram for Testing Conveyor Belts (Original in Slovak). Patent Application 50037-2020, 3 September 2020. ÚPV SR.

31. Fedorko, G.; Molnar, V.; Marasova, D.; Grincova, A.; Dovica, M.; Zivcak, J.; Toth, T.; Husakova, N. Failure analysis of belt conveyor damage caused by the falling material. Part I Exp. Meas. Regres. models Eng. Fail. Anal. 2014, 36, 30-38. 